\title{
A INCIDÊNCIA DO DIREITO INTERNACIONAL PENAL EM CASOS DE EXTRADIÇÃO JULGADOS PELO STF: ANÁlISE CRÍTICA
}

TESE DE DOUTORADO

ORIENTADORA:

PROFESSORA ASSOCIADA DR a CLÁUDIA PERRONE MOISÉS

FACULDADE DE DIREITO DA UNIVERSIDADE DE SÃO PAULO 


\section{A INCIDÊNCIA DO DIREITO INTERNACIONAL PENAL EM CASOS DE EXTRADIÇÃO JULGADOS PELO STF: ANÁlISE CRÍTICA}

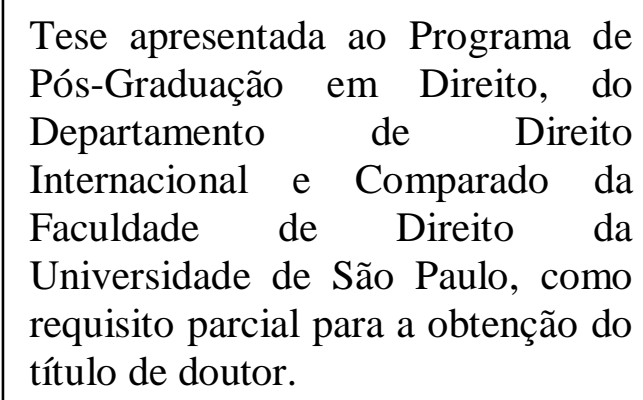

ORIENTADORA: PROFESSORA ASSOCIADA DR. a CLÁUDIA PERRONE MOISÉS

FACULDADE DE DIREITO DA UNIVERSIDADE DE SÃO PAULO

- SÃO PAULO -

- 2014 - 


\title{
RESUMO
}

\begin{abstract}
Alguns casos de extradição julgados pelo STF possuem especial relevância por apreciarem a ocorrência dos crimes internacionais. Assim, o estudo dessas decisões mostra-se importante para que se possa averiguar o efetivo exercício do direito internacional penal, que regula o tratamento especial dado a estes crimes. A presente Tese tem por objetivo averiguar a incidência das normas de direito internacional penal nos julgamentos do STF de pedidos de extradição. Apresenta-se, ainda, o impacto que o entendimento firmado nesses casos tem surtido no julgamento de outras ações, inclusive por outras esferas do Poder Judiciário brasileiro. Também é possível realizar um comparativo com o quanto decidido no julgamento da ADPF $n^{\circ} 153$, em que se reafirmou a validade da lei de anistia brasileira, que, por sua vez, extinguiu a punibilidade dos crimes internacionais cometidos durante o Regime Militar no Brasil. Por fim, a partir desses estudos, enfatiza-se a necessidades de dar efetiva aplicação ao direito internacional penal nos julgamentos realizados no âmbito do STF.
\end{abstract}

Palavras-chave: Direito Internacional Penal - Crimes internacionais - Extradição - Leis de anistia - Supremo Tribunal Federal. 


\begin{abstract}
Some extradition cases trialed at Brazil' Supreme Court of Justice show special relevance because they deal with international crimes. Therefore, the study of these judicial decisions is important so that it can be possible to verify the effectiveness of International Criminal Law, which regulates the special treatment given to those crimes. The present Thesis aims to examine the incidence of the rules and principles of international criminal law by Brazilian Supreme Court at extradition trials. It also presents the impacts of the understanding exposed in those trials on other cases and actions, subjected to other organs of Brazil's Judiciary system. It is either possible to create a comparative between the jurisprudence of extradition cases and what has been decided at the ADPF $\mathrm{n}^{\circ} 153$, reaffirming Brazilian amnesty law, which has granted amnesty to international crimes committed during Brazil's military regime. Finally, trough these reviews, it emphasizes the need to give real enforcement to international criminal law when Brazil's Supreme Court analyzes extradition requests.
\end{abstract}

Key-words: International Criminal Law - International crimes - Extradition - Amnesty laws - Brazil's Supreme Court of Justice. 


\section{RÉSUMÉ}

Quelques cas d'extradition jugés par la Cour Supreme du Brésil sont très importants car ils font référence aux crimes internationaux. De cette façon, l'étude de ces décisions est essential pour vérifier l'effectif exercice du droit international pénal, qui régule le traitement espécial donné à ces crimes. La présente Thèse a le but de examiner l'incidence des normes du droit international pénal dans les jugements d'extradition devant la Cour Supréme. On présente, encore, l'impact de Sa vue dans le jugement d'autres types d'action juridique, y inclus celui donné pour d'autres sphères du système judiciaire brésilien. Il est aussi possible d'établir un comparatif avec ce qui a été decidé au jugement de la ADPF ${ }^{\circ}$ 153, où la validité de la loi d'amnistie brésilienne a été reaffirmée, en confirmant la comprehénsion que les crimes internationaux pratiqués pendant le Régime Militaire brésilien ne sont pas punissable. Finalement, à partir de ces études, on renforce la necessité de donner une effective application au droit international pénal dans les jugements realisés par la Cour Suprème.

Mots-clés: Droit International Pénal - Crimes internationaux - Extradition - Loi d'amnistie - Cour Suprème du Brésil. 


\section{INTRODUÇÃO}

A presente Tese aborda a intersecção existente entre o direito internacional penal e a extradição no Brasil, a partir da análise da jurisprudência do Supremo Tribunal Federal, órgão competente para o julgamento dos pedidos de extradição no país.

Para tanto, em um primeiro capítulo, é realizada uma apresentação teórica referente ao instituto da extradição. Nesta ocasião, analisa-se seu conceito, histórico, princípios, procedimento e sua aplicação no direito internacional e interno. Dá-se, então, especial ênfase a algumas exceções ou requisitos à concessão da extradição, que depois se mostrarão relevantes aos objetivos da presente Tese, quais sejam, a necessidade de haver dupla incriminação, a impossibilidade de se extraditar alguém para ser julgado por crime prescrito e a proibição da extradição por crime político.

No segundo capítulo, apresenta-se o direito internacional penal e suas especificidades, especialmente no que tange ao crime contra a humanidade e à sua interrelação com o direito internacional dos direitos humanos. Analisa-se, ainda, a importância da incorporação das normas do direito internacional penal aos ordenamentos jurídicos nacionais, a fim de dar maior efetividade a este ramo do direito.

Ao final desta parte, insere-se a extradição como instrumento de alta importância para o desenvolvimento do direito internacional penal.

Ao terceiro capítulo, o enfoque é direcionado ao Supremo Tribunal Federal (STF) e à seleção de casos de extradição com vistas a se dar suporte à proposta desta Tese. Nesta ocasião, é feita uma análise descritiva dos casos de extradição escolhidos e dos votos exarados por ocasião do seu julgamento, os quais serão objeto de análise crítica no último capítulo.

A apreciação do julgamento da lei de anistia brasileira, por meio da Arguição de Descumprimento de Preceito Fundamental (ADPF) no 153 é o objetivo do quarto capítulo, 
em comparação com o quanto determinado pela Corte Interamericana de Direitos Humanos no caso Gomes Lund e outros v. Brasil.

Por fim, o capítulo quinto visa demonstrar a efetiva incidência ou não do direito internacional penal pelo STF nos casos de extradição e o impacto da jurisprudência da Corte nesses casos tanto na possibilidade de um novo julgamento quanto à lei de anistia quanto à possibilidade do processamento criminal de agentes públicos pelo cometimento de crimes na época do Regime Militar brasileiro.

Por fim, pretende-se demonstrar de que forma o Judiciário brasileiro pode contribuir para uma aplicação mais efetiva das regras desse ramo do direito quando deparados com pedidos de extradição.

Tais objetivos têm sua justificativa primordial no fato de tratar-se, em última análise, de mais uma contribuição à defesa e à promoção dos direitos humanos e à manutenção da paz e segurança internacionais.

Nas palavras de Luigi Ferrajoli (2002, p. 54), a paz pelo direito significa "uma limitação efetiva da soberania dos Estados por meio de introdução de garantias jurisdicionais contra violações da paz, externamente, e dos direitos humanos, internamente". E é nesse sentido que o direito internacional penal pode contribuir para a manutenção da paz, vez que representa uma atuação efetiva da comunidade internacional contra condutas violadoras de direitos humanos.

Ciente de que o direito internacional penal decorre indubitavelmente de um processo de busca de maior proteção aos direitos humanos, portanto, avaliar os julgados de extradição no STF se mostra de crucial importância para a ciência jurídica, vez que buscará apresentar formas de dar maior efetividade a esse ramo do direito no ordenamento jurídico brasileiro. Assim, a aplicação consciente do direito internacional penal pelo Judiciário do Brasil só poderá colaborar para a realizabilidade dos direitos humanos no país e, consequentemente, no plano internacional.

A escolha dos casos de extradição, para análise da aplicação do direito internacional penal, se dá porque no âmbito da apreciação deste instituto, o Judiciário brasileiro tem permitido o julgamento de crimes internacionais cometidos em território 
estrangeiro, os quais muito se assemelham a crimes internacionais cometidos em território brasileiro e que permanecem até hoje sem resposta, demonstrando verdadeira contradição.

Os entendimentos assumidos nos julgamentos dos casos de extradição selecionados são fundamentais para se colocar em discussão questões atuais do direito internacional, do direito constitucional e do direito penal, as quais também se relacionam ao posicionamento apresentado pelo STF em 2010 quanto à revisão da lei de anistia brasileira e quanto às possibilidades de uma nova apreciação futura do tema (por meio da $\operatorname{ADPF}^{\circ}{ }^{\circ} 320$ ).

Sabe-se que há diversos registros na ciência jurídica brasileira de discussões acerca da aplicação do direito internacional pelos órgãos internos. Assim, é comum deparar-se com estudos variados que tratam dos conflitos enfrentados pelo direito internacional quando da sua incorporação pelos ordenamentos jurídicos dos países.

Dentro dessa discussão, também aparecem em maior número os debates concernentes à cooperação judiciária internacional, em especial em matéria penal, na qual se apresenta a o procedimento da extradição e seus desafios. No entanto, nessas discussões, pouco ou quase nada se vê acerca da aplicação do direito internacional penal na prática do direito brasileiro, seja no tocante à análise dos pontos em que há efetiva aplicação do direito internacional penal pelo Judiciário brasileiro, seja quanto a uma avaliação crítica sobre as situações e os meios em que o direito internacional penal deveria ou poderia ser aplicado na prática judiciária brasileira.

Dessa forma, a presente Tese ambiciona poder contribuir com a ciência jurídica brasileira com o objetivo original de tratar amplamente de tais questionamentos. Em resumo, esta tese de doutorado busca evidenciar se há ou não aplicação efetiva do direito internacional penal pelo STF nos casos de extradição. Se sim, em que medida e de que forma essa aplicação contribui para a real justiça e para o desenvolvimento e fortalecimento das regras do direito internacional. Se não, de que maneira e em que grau poderiam ou deveriam ser aplicados aspectos do direito internacional penal, de forma a dar maior força ao direito internacional e, em última análise, efetivamente cooperar para a realização dos direitos humanos, tanto no plano interno quanto no cenário internacional.

Ao final, portanto, as discussões aqui apresentadas perpassam os seguintes questionamentos: a) qual a importância dos casos de extradição ao direito internacional 
penal?; b) é recorrente a utilização do instituto da extradição para a persecução de crimes internacionais?; c) de que maneira tem decidido o STF nesses casos?; d) é possível dizer que a Corte suprema brasileira busca aplicar o direito internacional penal ao julgar os casos de extradição?; e) há uma contradição entre o que foi decidido nos casos de extradição e a improcedência da ADPF $\mathrm{n}^{\circ}$ 153?; f) é possível enxergar uma mudança de posicionamento no STF quanto à revisão da lei de anistia?; g) a jurisprudência dos casos de extradição podem contribuir para tanto?. 


\section{CONCLUSÃO}

A análise e as propostas elaboradas neste último capítulo confirmam que muitas vezes o Direito é tratado como um mero instrumento, que, no máximo, responde a pressões externas para tentar calar ou acalmar alguns focos de insatisfação social, estando mais preocupado com as consequências imediatas do que com sua consistência ou continuidade (BERMAN, 2006, p. 56).

No entanto, o Direito deve ultrapassar a vontade do legislador, para alcançar também a razão e a consciência da comunidade e os seus usos e costumes (BERMAN, 2006, p. 22). Deve ser capaz de enfrentar os problemas estruturais da sociedade e solucioná-los. Assim, não poderia ser compreendido como um simples instrumento de dominação econômica ou política, mas deve ser visto como um importante componente da estrutura básica da sociedade ocidental, pois é, ao mesmo tempo, reflexo e determinante dos desenvolvimentos político e econômico (BERMAN, 2006, p. 57).

Celso Lafer (2005, p. 28-29) observa a importância de se analisar os princípios referentes à realidade internacional tendo em vista o ângulo externo, com vistas à cooperação internacional. Lembra o autor o ensinamento de Bobbio, ao afirmar que Direito e Poder são duas faces da mesma moeda, pois Poder sem normas é poder arbitrário e Direito sem poder é direito impotente.

Neste aspecto, a atuação do STF tem fundamental importância, já que este tribunal é o maior intérprete do ordenamento jurídico brasileiro e tem ganhado cada vez mais notoriedade. Apesar da polêmica quanto à extensão de suas funções - se interfere ou não as atribuições do Poder Legislativo - verifica-se uma verdadeira necessidade de atuação do Judiciário a fim de dar cumprimento aos compromissos assumidos pelo país internacionalmente.

Nos ensinamentos de Ricoeur (1995, p. 166), o julgamento deve ser um ato de reconhecimento, que afasta a imposição da violência. Ora, só poderá ter esse efeito de reconhecimento a decisão que de fato decidir algo. 
Nesse passo, os julgados do STF nos casos de extradição analisados merecem especial atenção, pois, ainda que não representem explícita aceitação do direito internacional penal pelo Judiciário brasileiro, demonstram que é possível se dar maior efetividade a suas normas e indicam uma forte tendência neste tribunal de permitir o julgamento de graves violações de direitos humanos.

O direito internacional penal seria resultado da identificação dos direitos humanos com os valores mais importantes da convivência humana. No entanto, essa hierarquia de valores prevalecente no meio social nem sempre coincide com a consagrada no ordenamento positivo, havendo sempre uma tensão dialética entre a consciência jurídica da coletividade e as normas editadas pelo Estado (COMPARATO, 2010, p. 38-39). Daí, a importância da efetiva atuação do STF, que não pode ser considerado mero intérprete do Direito.

Retome-se, ainda, o contexto da Teoria da Argumentação, da Hermenêutica Contemporânea, da construção de sentido na lógica do razoável e do sopesamento de princípios abstratos à luz do caso concreto. Nesse sentido, permite-se afirmar que a tarefa interpretativa é a de atualizar o conteúdo da norma, não havendo mais distinção entre o interpretar e o aplicar o Direito.

Trata-se de critérios a fundamentarem as argumentações, diretamente relacionadas ao contexto histórico, social, político e internacional ${ }^{1}$. Por fim, sublinhe-se que o desafio contemporâneo da hermenêutica jurídica é o de justificar e motivar as decisões. Ou seja, a tarefa do aplicador do direito é a de produzir argumentos, respaldados em critérios mínimos que dão sentido e legitimam sua interpretação, sempre em consonância com os valores maiores da dignidade da pessoa humana e da sociedade fraterna, pluralista e sem preconceitos. Afinal, lembrando-se o magistério de Celso Lafer (2003, p. 30):

O juízo, entendido como faculdade de subsumir o particular no geral, é um dos temas fundamentais do Direito, pois uma das características da experiência jurídica moderna é o processo por

\footnotetext{
${ }^{1}$ Relembre-se aqui a cara noção do costume e da prática em Direito Internacional, que explicitam a complexidade do estudo do tema do crime da prática do racismo. Em Direito Internacional, é o costume a prática reiterada e obrigatória de dada conduta. Tal reforça-nos a importância de recorrermos aos contextos históricos, sociais, culturais, políticos e econômicos, para se verificar, adequadamente, a conceituação do racismo, não esteirado na noção de raça, mas sim nas práticas discriminatórias e preconceituosas.
} 
meio do qual o caso concreto é qualificado pela norma geral. A lógica do razoável do paradigma da filosofia do direito explorou amplamente, em matéria de hermenêutica jurídica, as dificuldades de subsunção. Entretanto, sempre partiu do pressuposto de que existe um geral, ao qual se possa razoavelmente recorrer.

O julgamento da ADPF $n^{\circ} 153$ deu ao STF mais uma oportunidade de se pronunciar no sentido de dar maior efetividade ao Direito. No entanto, ao se esquivar da responsabilidade de decidir, em última análise, a Corte o esvaziou de sentido, perpetuando a incapacidade de agir do Direito.

A lei de anistia brasileira certamente não é legítima do ponto de vista internacional, ao menos não da forma como vem sendo interpretada, ou seja, de forma ampla e irrestrita. Pode-se duvidar ainda da sua legitimidade tendo em vista o plano interno, uma vez que, apesar do entendimento do STF de que a lei de anistia brasileira é fruto de um acordo social, um consenso entre governo e oposição, diversas são as vozes que contestam essa afirmação. Além disso, o próprio processo de aprovação da lei gera dúvidas quanto à sua legitimidade democrática, uma vez que aprovada por um Legislativo dominado pela pressão dos militares que ainda estavam no governo.

A verdade é que passamos de uma noção de soberania muito forte para uma noção de universalidade. Mas continuamos vivendo com padrões internos, quando temos que responder questões no plano internacional, o que gera um grande conflito. Talvez seja importante aceitar padrões universais, ainda que não idênticos ou distintos dos padrões internos para que se possa avançar na concepção de um indivíduo internacional, que tem direitos no mundo todo.

Não é possível manter-se a par da evolução das discussões no plano internacional, sob pena de o país terminar alijado das relações internacionais e impedir a eficiência da justiça. Plano esse que também contempla um padrão mínimo de garantias a serem respeitadas.

Cláudia Perrone Moisés, em sua tese de livre-docência, analisa as lições de Mireille Delmas-Marty ${ }^{2}$ em curso proferido no Collège de France, no qual afirmou que a

\footnotetext{
${ }^{2}$ DELMAS-MARTY, Mireille. Cours: Vers une communauté des Valeurs?-Les Interdits fondateurs. In:
} Cours e travaux du Collège de France, 2006-2007, Annuaire 107e année, p. 538, 539 e 549. 
transformação da comunidade internacional em uma comunidade humana, fundada em valores comuns, a partir dos "interditos fundadores", é seletiva e variável, pois decorre de dois pares conflitantes: proibir/justificar e punir/perdoar. No que diz respeito à primeira dicotomia, Delmas-Marty teria analisado três paradigmas de nossa época: os crimes de guerra (limitar o inumano), a "guerra contra o crime" (legitimar o inumano) e o crime contra a humanidade (construir a humanidade como valor).

Quanto à dicotomia punir perdoar, existem três debates importantes em torno da questão, que exprime a relação entre justiça e paz social: encontrar um equilíbrio entre responsabilidade e impunidade; identificar os responsáveis pelas transgressões e verificar a cadeia de responsabilidade nos crimes internacionais. Cabe determinar se entendemos privilegiar a paz (ordem política), a solidariedade (ordem social) ou a punição (ordem jurídico-moral). Dependendo da resposta, o equilíbrio será diferente entre a responsabilidade e impunidade, entre competência nacional e internacional, ou ainda, entre a punição e outras formas de sanção (reparação, conciliação) (apud PERRONE MOISÉS, 2009, p. 42-43).

Essa oportunidade de dar reconhecimento e efetividade ao Direito se renova com o ajuizamento de uma nova ADPF e a modificação na composição do STF. 


\section{BIBLIOGRAFIA}

ACCIOLY, Hildebrando, NASCIMENTO E SILVA, G.E. do e CASELLA, Paulo Borba. Manual de Direito Internacional Público, $17^{\mathrm{a}}$ Ed. São Paulo: Saraiva, 2009.

ALFONSO, César. La obligatoriedad de las decisiones de la Corte Interamericana de Derechos Humanos desde La perspectiva de distintos países de America del Sur. In: GRUPO LATINOAMERICANO DE ESTUDIOS SOBRE DERECHO PENAL INTERNACIONAL. Sistema interamericano de protección de los derechos humanos y derecho penal internacional. Fundação Konrad Adenauer, 2010, pp. 63-79. Disponível em: <http://www.department-ambos.unigoettingen.de/index.php/component/option,com_docman/Itemid,77/gid,132/task,cat_ view/>. Acesso em: 16.11.2011.

AMARAL JR., Alberto. A institucionalização internacional dos direitos humanos: conquistas e desafios. In: PIOVESAN, Flávia (org.). Direitos humanos, globalização econômica e integração regional - desafios do direito constitucional internacional. São Paulo: Max Limonad, 2002, pp. 637 a 650.

AMBOS, Kai. O marco jurídico da justiça de transição. In: AMBOS, Kai; ZILLI, Marcos; MOURA, Thereza Rocha de Assis e MOTECONRADO, Fabíola Girão. Anistia, Justiça e Impunidade: Reflexões sobre a Justiça de Transição no Brasil. Belo Horizonte: Fórum, 2010, pp. 21-132.

. A parte geral do direito penal internacional: bases para uma elaboração dogmática. Ed. Brasileira reformulada e atualizada. Tradução de Carlos Eduardo Adriano Japiassú e Daniel Andrés Raizman. São Paulo: RT, 2008.

AMBOS, Kai e ZILLI, Marcos. Apresentação. In: AMBOS, Kai; ZILLI, Marcos; MOURA, Thereza Rocha de Assis e MOTECONRADO, Fabíola Girão. Anistia, Justiça e Impunidade: Reflexões sobre a Justiça de Transição no Brasil. Belo Horizonte: Fórum, 2010, pp. 17-19. 
ARAÚJO, Nadia de. Prefácio. In: CASELA, Paulo Borba e SANCHEZ, Rodrigo Elian (orgs.). Cooperação Judiciária Internacional. Rio de Janeiro: Renovar, 2002, pp. 123.

ARENDT, Hannah. A Condição Humana. Rio de Janeiro: Forense Universitária, 1995.

_. Origens do Totalitarismo: anti-semitismo, imperialismo, totalitarismo. São Paulo: Companhia das Letras, 2000.

. Eichmann em Jerusalém: um retrato sobre a banalidade do mal. Tradução de José Rubens Siqueira. São Paulo: Companhia das Letras, 1999.

ARQUIDIOCESE DE SÃO PAULO. Brasil: Nunca Mais. Prefácio de Dom Paulo Evaristo Arns. Petrópolis: Vozes, 2011.

ASCENSIO, Hervé, DECAUX, Emmanuel e PELLET, Alain. Droit international pénal. Paris: Éditions A. Pedone, 2000.

BALTAZAR Jr., José Paulo. Extradição passiva na jurisprudência do STF. In: BALTAZAR Jr., José Paulo e LIMA, Luciano Flores de (orgs.). Cooperação jurídica internacional em matéria penal. Porto Alegre: Verbo Jurídico, 2010.

BASSIOUNI, M. Cherif e WISE, Edward M. Aut dedere aut judicare: the duty to extradite or prosecute in international law. Boston: M. Nijhoff, 1995.

BASSIOUNI, M. Cherif. International criminal law. Nova Iorque: Transnational Publishers, 1986.

Ideologically motivated offenses and the political offenses exception in extradition - a proposed juridical standard for an unruly problem. De Paul Law Review, vol. XIX, n. 2, 1969/1970, pp. 217-269.

BASTOS, Lucia Elena Arantes Ferreira Bastos. Anistia: as leis internacionais e o caso brasileiro. Curitiba: Juruá, 2009.

BECCARIA, Cesare. Dos delitos e das penas. São Paulo: CD Editora, 2004. 
BERMAN, Harold J. Direito e Revolução: a formação da tradição jurídica ocidental. São Leopoldo: Unisinos, 2006, p. 11-63.

BIANCHI, Andrea. State Responsibility and criminal liability of individuals. In: CASSESE, Antonio (coord.). The Oxford companion to international criminal justice. Nova Iorque: Oxford University Press, 2009, pp. 16-24.

BOBBIO, Norberto. A era dos direitos. Rio de Janeiro: Editora Campus, 2004.

. O problema da guerra e as vias da paz. São Paulo: Unesp, 2003.

BOURDON, William. La coopération judiciaire interétatique. In: ASCENSIO, Hervé, DECAUX, Emmanuel e PELLET, Alain. Droit international pénal. Paris: Éditions A. Pedone, 2000, pp. 921-931.

BRASIL. Supremo Tribunal Federal. Arguição de Descumprimento de Preceito Fundamental $n^{o}$ 153/DF. Relator: Min. Eros Grau. Julgado em: 29.04.2010. Disponível em: <http://redir.stf.jus.br/paginadorpub/paginador.jsp?docTP=AC\&docID=612960> . Acesso em: 16.11.2011.

BRASIL. Supremo Tribunal Federal. Extradição. Brasília: Secretaria de Documentação, Coordenadoria de Divulgação de Jurisprudência, 2006.

_. Supremo Tribunal Federal. Extradição $n^{o}$ 974-0 República Argentina. Relator para o acórdão: Ministro Ricardo Lewandowski. Julgamento em 06 ago 2009.

CARNEIRO, Camila Tagliani. A extradição no ordenamento jurídico brasileiro. São Paulo: Memória Jurídica Editora, 2002.

CASELA, Paulo Borba e SANCHEZ, Rodrigo Elian (orgs.). Cooperação Judiciária Internacional. Rio de Janeiro: Renovar, 2002.

CASSESE, Antonio. International Criminal Law, $2^{\mathrm{a}}$ Ed. Nova Iorque: Oxford University Press, 2008. 
- Existe um conflito insuperável entre soberania dos Estados e justice penal internacional?. In: CASSESE, Antonio e DALMAS-MARTY, Mireille (org.). Crimes internacionais e jurisdições internacionais. Tradução de Silvio Antunha. Barueri: Manole, 2004, pp. 267-327.

_. International Criminal Law. In: EVANS, Malcolm D. International Law. Oxford: Oxford University, 2003, pp. 721-756.

CASTRO, Joelíria Vey de. Extradição: Brasil \& Mercosul. $1^{\mathrm{a}}$ ed. (ano 2003), $3^{\mathrm{a}}$ tir. Curitiba: Juruá, 2006.

CHARNEY, Jonathan I. International Criminal Law and the Role of Domestic Courts. The American Journal of International Law, vol. 95, nº 1 (jan, 2001), pp. 120-124.

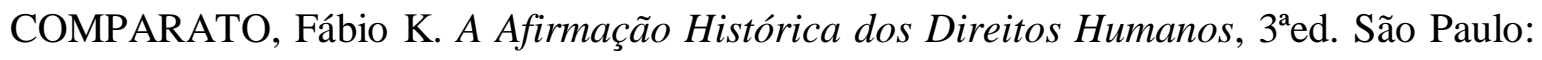
Saraiva, 2003.

CORTE INTERAMERICANA DE DIREITOS HUMANOS. Caso Gomes Lund e outros contra Brasil. Decisão de 24 de novembro de 2010. Disponível em: $<$ http://www.corteidh.or.cr/docs/casos/articulos/seriec_219_esp.pdf>. Acesso em: 25.11.2011.

DELMAS-MARTY, Mireille. O direito penal do inumano. São Paulo: Fórum, 2014.

_. Cours: Vers une communauté des Valeurs?-Les Interdits fondateurs. Cours e travaux du Collège de France, 2006-2007, Annuaire 107e année, p. 538, 539 e 549.

_. La responsabilité pénale em échec - prescription, amnistie, immunités. In: CASSESE, Antonio e DELMAS-MARTY, Mireille (org.). Jurisdictions nationales et crimes internationaux. Paris: PUF, 2002, pp. 613-652.

_. Comparative criminal Law as a necessary tool for the application of international criminal Law. In: CASSESE, Antonio (coord.). The Oxford companion to international criminal justice. Nova Iorque: Oxford University Press, 2009, pp. 97103. 
DEL'OLMO, Florisbal de Souza. A extradição no alvorecer do século XXI. Rio de Janeiro: Renovar, 2007.

_. Extradição no Brasil: casos de criminosos internacionais e a precipitada deportação dos atletas cubanos em 2007. Pensar, Fortaleza, vol. 13, nº 1, jan/jun. 2008.

DUGART, John e VAN DEN WYNGAERT, Christine. Reconciling extradition with human rights. The American Journal of International Law, vol. 92, $\mathrm{n}^{\mathrm{o}} 2$ (abr., 1998), pp. 187-212.

FARIA, Antonio Bento de. Código Penal Brasileiro comparado. Rio de Janeiro: Distribuidora Récord Ed., 1958, 7v.

FASANO, Renata. A competência repressiva universal no direito internacional penal. Dissertação de mestrado apresentada à Faculdade de Direito da Universidade de São Paulo, 2011.

FERRAJOLI, Luigi, A soberania no mundo moderno. São Paulo: Martins Fontes, 2002.

FERREIRA, Luciano Vaz e TROTTA, Sandro Brescovit. Da obrigatoriedade de cooperar e os recursos cabíveis em casos de descumprimento de tratado internacional. In: BALTAZAR Jr., José Paulo e LIMA, Luciano Flores de (orgs.). Cooperação jurídica internacional em matéria penal. Porto Alegre: Verbo Jurídico, 2010.

FICHET-BOYLE, Isabelle e MOSSÉ, Marc. L'obligation de prendre dês mesures internes nécessaires à La prévention et à la répression des infractions. In: ASCENSIO, Hervé, DECAUX, Emmanuel e PELLET, Alain. Droit international pénal. Paris: Éditions A. Pedone, 2000, pp. 871-885.

FRULLI, Micaela. O direito internacional e os obstáculos à implantação de responsabilidade penal para crimes internacionais. In: CASSESE, Antonio e DELMAS-MARTY, Mireille (org.). Crimes internacionais e jurisdições internacionais. Tradução de Silvio Antunha. Barueri: Manole, 2004, pp. 267-327.

. Le droit international e les obstacles à la mise em ouvre de la responsabilité pénale pour crimes internationaux. In: CASSESE, Antonio e DELMAS-MARTY, Mireille 
(org.). Crimes internationaux et juridictions internationales. Paris: PUF, 2002, pp. 215-253.

GUIMARÃES, Francisco Xavier da Silva. Medidas compulsórias, a deportação, a expulsão e a extradição. $2^{\text {a }}$ ed. Rio de Janeiro: Forense, 2002.

JESSBERGER, Florian. International v. National Prosecution of International Crimes. In: CASSESE, Antonio (coord.). The Oxford companion to international criminal justice. Nova Iorque: Oxford University Press, 2009, pp. 208-215.

LAFER, Celso. A Internacionalização dos direitos humanos: Constituição, racismo e relações internacionais. São Paulo: Manole, 2005.

A identidade internacional do Brasil e a política externa brasileira: passado, presente e futuro, 2. ed., São Paulo: Perspectiva, 2004.

- A Reconstrução dos Direitos Humanos - Um diálogo com o Pensamento de Hanna Arendt. Companhia das Letras, 2003.

_. Resistência e Realizabilidade da Tutela dos Direitos Humanos no Plano Internacional no Limiar do Século XXI. In: AMARAL Jr., Alberto do, e MOISÉS, Cláudia Perrone (orgs). O Cinqüentenário da Declaração Universal dos Direitos do Homem. São Paulo: Edusp/Fapesp, 1999, pp. 441-52.

LEVY-BRUHL, Henri. Les délits politique: recherche d'une définition. Revue française de sociologie, vol. 5, no 2 (abr-jun, 1964), pp. 131-139.

LOIS, Cecilia Caballero e MARICATO, Carla Andrade. Fragmentos de memória, restos da barbárie: ou sobre o que se pode perdoar e o que não se deve esquecer. Ethic@, vol. 7, no $2, \operatorname{dez} / 2008$, p. 295/307.

MALLINDER, Louise. Exploring the practice of States in introducing amnesties. In: AMBOS, Kai, LARGE, Judith e WIERDA, Marieke (org.). Building a Future on Peace and Justice: Studies on Transitional Justice, Peace and Development The Nuremberg Declaration on Peace and Justice. Berlim: Springer, 2008, pp. 127-171. 
MATUTE, Javier Dondé. El concepto de impunidad: leyes de amnistía y otras formas estudiadas por la Corte Interamericana de Derechos Humanos. In: GRUPO LATINOAMERICANO DE ESTUDIOS SOBRE DERECHO PENAL INTERNACIONAL. Sistema interamericano de protección de los derechos humanos y derecho penal internacional. Fundação Konrad Adenauer, 2010, pp. 263-293. Disponível em: <http://www.department-ambos.unigoettingen.de/index.php/component/option,com_docman/Itemid,77/gid,132/task,cat_ view/>. Acesso em: 27.11.2011.

MELLO, Celso Duvivier de Albuquerque. Curso de Direito Internacional, vol. 1 e 2. São Paulo: Renovar, 2002.

MERCIER, ANDRÉ. L'extradition. Recueil des Cours, vol. 33, 1930, Paris.

MIRANDA, Neemias Carvalho. Extradição: decisões contraditórias no Supremo Tribunal Federal. Rio de Janeiro: Lumen Juris, 2010.

MORE, Rodrigo Fernandes. A prevenção e solução de litígios internacionais no Direito Penal Internacional: fundamentos, histórico e estabelecimento de uma Corte Penal Internacional (Tratado de Roma, 1998). In: MERCADANTE, Araminta de Azevedo e MAGALHÃES, José Carlos (coord.). Solução e prevenção de litígios internacionais, vol. II. Porto Alegre: Livraria do Advogado, 1999, pp. 317-367.

MORO, Sérgio Fernando. Cooperação jurídica internacional em casos criminais: considerações gerais. In: BALTAZAR Jr., José Paulo e LIMA, Luciano Flores de (orgs.). Cooperação jurídica internacional em matéria penal. Porto Alegre: Verbo Jurídico, 2010.

PAMPLONA, Gustavo. Crime político no Estado Democrático de Direito: o nocrim a partir de Hannah Arendt. MPMG Jurídico, no 18, out/nov/dez - 2009, p. 22-27.

PELLEGRINI, Lisandro. El incumplimento de las sentencias de la Corte Interamericana de Derechos Humanos. In: GRUPO LATINOAMERICANO DE ESTUDIOS SOBRE DERECHO PENAL INTERNACIONAL. Sistema interamericano de protección de los derechos humanos y derecho penal internacional. Fundação Konrad Adenauer, 2010, pp. 81-102. Disponível em: <http://www.department-ambos.uni- 
goettingen.de/index.php/component/option,com_docman/Itemid,77/gid,132/task,cat_ view/>. Acesso em: 16.11.2011.

PEREIRA, Lafayette Rodrigues. Princípios de Direito Internacional. Rio de Janeiro: J. Ribeiro dos Santos, 1902.

PERRONE MOISES, Cláudia. O princípio de complementaridade no Estatuto do Tribunal Penal Internacional e a soberania contemporânea, Política Externa, vol. 8, n. 4, mar./abr./mai., 2000, pp. 3-11.

- A relação entre tribunais nacionais e tribunais penais internacionais. Boletim IBCCRIM, ano 8, n. 91

Antecedentes históricos do estabelecimento do Tribunal Penal Internacional. Revista da Faculdade de Direito da USP, abril de 2003.

- Imunidades de chefes de Estado e crimes internacionais. Tese de Livre docência apresentada ao Departamento de Direito Internacional e Comprado da Faculdade de Direito da Universidade de São Paulo. São Paulo, 2009.

_. Direito Internacional Penal: Imunidades e Anistias. Barueri, SP: Manole, 2012.

PERRUSO, Camila Akemi. Responsabilidade internacional por violações de direitos humanos: a condenação do Brasil no caso da guerrilha do Araguaia. Boletim IBCCRIM. São Paulo: IBCCRIM, ano 18, n. 219, p. 01-02, 2011.

_ _ Desaparecimento forçado de pessoas, verdade e memória. Boletim IBCCRIM. São Paulo: IBCCRIM, ano 18, n. 219, p. 17, fev. 2011.

- O desaparecimento forçado de pessoas no sistema interamericano de direitos humanos - direitos humanos e memória. Dissertação de mestrado apresentada à Faculdade de Direito da Universidade de São Paulo, 2010.

PERTENCE, J. P. SEPÚLVEDA. Liberdade e direito de asilo. Anais da $8^{\circ}$ Conferência Nacional da OAB. 1980. 
PHILLIPS, R. Stuart. The political offence exception and terrorism: its place in the current extradition scheme and proposals for its future. Dickinson Journal of International Law, v. 15, 1997.

PIOVESAN, Flávia. Direitos humanos e o direito constitucional internacional. $13^{\mathrm{a}} \mathrm{ed} .2^{\mathrm{a}}$ tiragem. São Paulo: Saraiva, 2012.

PONCELA, Pirrette. L'imprescriptibilité. In: ASCENSIO, Hervé, DECAUX, Emmanuel e PELLET, Alain. Droit international pénal. Paris: Éditions A. Pedone, 2000, pp. 887895.

POUTIERS, Mikäel. L'extradition des auteurs d'infractions internationales. In: ASCENSIO, Hervé, DECAUX, Emmanuel e PELLET, Alain. Droit international pénal. Paris: Éditions A. Pedone, 2000, pp. 933-950.

RAMOS, Andre de Carvalho. Responsabilidade Internacional por Violação de Direitos Humanos. Rio de Janeiro: Renovar, 2004.

_. O diálogo das cortes: o Supremo Tribunal Federal e a Corte Interamericana de Direitos Humanos. In: AMARAL JR., Alberto e JUBILUT, Liliana Lyra (org.). $O$ STF e o direito internacional dos direitos humanos. São Paulo: Quartier Latin, 2009a, pp. 805-850.

- Supremo Tribunal Federal brasileiro e o controle de convencionalidade: levando a sério os tratados de direitos humanos. Revista da Faculdade de Direito, Universidade de São Paulo, v. 104, 2009b, pp. 241-286.

. Crimes da ditadura militar: a ADPF 153 e a Corte Interamericana de Direitos Humanos. In: GOMES, Luiz Flávio e MAZZUOLI, Valerio de Oliveira (org.). Crimes da Ditadura Militar: uma análise à luz da jurisprudência atual da Corte Interamericana de Direitos Humanos: Argentina, Brasil, Chile, Uruguai. São Paulo: RT, 2011, pp. 174-225.

_. Processo internacional dos direitos humanos. São Paulo: Saraiva, 2013.

A interpretação internacional dos Direitos Humanos: choque ou diálogo com o Supremo Tribunal Federal?. In: BAPTISTA, Luiz Olavo e Ferraz Jr, Tércio Sampaio 
(org.). Novos caminhos do direito no século XXI - Direito internacional, filosofia jurídica e política, dogmática jurídica e direitos fundamentais. 1ed. Curitiba: juruá, 2012, v. 1, pp. 281-337.

_. O novo direito internacional privado e o conflito de fontes na cooperação jurídica internacional. Revista da Faculdade de Direito da Universidade de São Paulo, v. 108, 2013, pp. 621-647.

REALE. Egídio. Le droit d'asile. Recueil de Cours, v. 63, 1938, pp. 469-597.

REZEK, José Francisco. Direito Internacional Público - Curso Elementar. $6^{\text {a }}$ Ed. São Paulo: Saraiva, 1996.

RICOUER, Paul. O Acto de Julgar. O Justo ou a essência da justiça. Lisboa: Instituto Piaget, 1995. p. 163-169.

RIBEIRO, Gleisse. O Supremo Tribunal Federal e o controle dos processos de extradição. Revista do Programa de Mestrado em Direito do UniCEUB. Brasília, vol. 2, n. 1, p. 261-279, jan./jun. 2005.

RUSSOMANO, Gilda. A extradição no direito internacional e no direito brasileiro. $3^{\circ} \mathrm{Ed}$. São Paulo: RT, 1981.

Aspectos da extradição no direito internacional público. Rio de Janeiro: José Konfino, 1960.

SCHWARZENBERGER, Georg. The problem of an international criminal law. In: MUELLER, Gerhard e WISE, Eward M. International criminal law, Nova Iorque: New York University, 1965.

SHAW, Malcolm N. International Law. $5^{\text {a }}$ Ed. Cambridge: Cambridge University Press, 2003.

SHECAIRA, Sérgio Salomão e CORRÊA JR, Alceu. Teoria da pena: finalidades, direito positivo, jurisprudência e outros estudos de ciência criminal. São Paulo: Editora Revista dos Tribunais, 2002. 
SOARES, Guido Fernando Silva. Legitimidade de uma guerra preventiva, em pleno 2003 ?. Política Externa, vol. 12, n. 1, 2003.

SWART, A. H. J. Refusal of extraditions and the UN model treaty on extradition. Netherlands Yearbook of International Law, vol. 23, 1992.

TIBURCIO, Carmen e BARROSO, Luís Roberto. Algumas questões sobre a extradição no direito brasileiro. Brasilia, ano 38, nº 150, abr/jun. 2001.

TROTTA, Sandro Brescovit. Análise jurídica da Extradição de Battisti: uma (re)discussão sobre os paradigmas do direito internacional. In BALTAZAR Jr., José Paulo e LIMA, Luciano Flores de (orgs.). Cooperação jurídica internacional em matéria penal. Porto Alegre: Verbo Jurídico, 2010.

VAN DEN WYNGAERT, Christine. The political offence exception to extradition. 1980.

ZILLI, Marcos; MOURA, Thereza Rocha de Assis e MOTECONRADO, Fabíola Girão. A justiça de transição no Brasil - um caminho ainda a percorrer. AMBOS, Kai; ZILLI, Marcos; MOURA, Thereza Rocha de Assis e MOTECONRADO, Fabíola Girão. Anistia, Justiça e Impunidade: Reflexões sobre a Justiça de Transição no Brasil. Belo Horizonte: Fórum, 2010, pp. 133-195. 